\title{
High-throughput fluorescent assay for inhibitor screening of proteases from RNA viruses
}

\author{
Bara Cihlova $^{1}$, Andrea Huskova ${ }^{1}$, Jiri Böserle, Radim Nencka, Evzen Boura*, Jan Silhan* \\ Institute of Organic Chemistry and Biochemistry of the Czech Academy of Sciences
}

\author{
${ }^{1}$ Co-first author \\ *To whom correspondence should be addressed: \\ jan.silhan@uochb.cas.cz; evzen.boura@uochb.cas.cz
}

\begin{abstract}
Spanish flu and other influenza outbreaks, the recent Zika epidemics, and the ongoing COVID19 pandemic are the most profound examples of severe widespread diseases that are caused by RNA viruses. Perhaps less well known yet dangerous RNA viruses cause deadly diseases such as polio, Ebola, measles, rubella, yellow fever, dengue fever and many others. To combat a particular viral disease by diminishing its spread and number of fatal cases, effective vaccines and antivirals are indispensable. Therefore, quick access to the means of discovery of new treatments for any epidemic outbreak is of great interest and in vitro biochemical assays are the basis of drug discovery. The recent outbreak of the coronavirus pandemic caused by severe acute respiratory syndrome coronavirus 2 (SARS-CoV-2) demands an affordable and reliable assay for testing antivirals. Here, we developed a quick and inexpensive high-throughput fluorescent assay to test inhibitors of viral proteases. Accordingly, we employed this assay to sample inhibitors for papain-like protease from SARS-CoV-2. In addition, we validated this assay for screening inhibitors of flaviviral protease from the tickborne encephalitis virus to emphasize a broad range of applications of our approach. This fluorescent high-throughput assay is based on fluorescent energy transfer (FRET) between two distinct fluorescent proteins (eGFP and mCherry) connected via a substrate polypeptide. When the substrate is cleaved, FRET is abolished and the change in fluorescence corresponds to reaction progress. Our data show that this assay can be used for testing the inhibitors in the 96 or 384
\end{abstract}

well plates format with robust and reproducible outcomes.

Keywords: high-throughput screening, virus, drug, discovery, protease, SARS-CoV-2, Flavivirus

\section{Introduction}

RNA viruses are considered to be one of the most severe threats to the human population and quality of life [1]. Since the beginning of this millennium, we have witnessed at least 60 epidemic outbreaks around the world, mostly caused by RNA viruses. Excluding the ongoing COVID-19 pandemic, these have caused more than a million deaths. The viruses responsible include: influenza virus, Ebola virus (EBOV), Zika virus (ZIKV), yellow fever virus (YFV), dengue viruses (DENV), measles, and coronaviruses such as SARS, MERS, and SARSCoV-2. The effect on human health is devastating, just as is the economic burden of these epidemics. The global cost of COVID-19 alone is astronomical and is predicted to surpass the GDPs of Germany, the UK and France combined. Therefore, the global importance of targeting the RNA viruses is indisputable.

The name and classification of RNA viruses originate from their genomic material which is composed of single-stranded or double-stranded RNA. Recent work has classified RNA viruses into 5 different orders with 47 families [2]. Although the nature of nucleic acid determines the classification of these viruses, more detailed classification is difficult due to the high mutation rate and recombination of the RNA viruses [3, 4]. 
RNA viruses have the highest mutation rates among all viruses, which often leads to the development of resistance against antivirals. These high mutation rates generate new species, where 2-3 novel viruses are discovered every year [5]. Understanding how mutation rates drive and shape the evolution of new and potentially deadly viruses that can cross interspecies boundaries is an ongoing topic of scientific interest [6].

Upon the infection of the host cell, viral RNA is replicated by viral RNA-dependent RNA polymerase and translated to one or more polyproteins. Subsequently, these polyproteins are processed by viral and host proteases into individual structural and nonstructural proteins. The presence and the functionality of viral enzymes, particularly proteases and polymerases, is a vital step in the replication and spread of the virus. A potential antiviral drug is correspondingly aimed at inhibiting the viral enzymes, thus limiting the spread of the virus. However, approved antivirals against RNA viruses are generally lacking, and only a few RNA viruses can be currently treated by approved antivirals: the influenza virus, the respiratory syncytial virus, and hemorrhagic viruses such as the Lassa mammarenavirus or the hepatitis $\mathrm{C}$ virus (HCV). Without antiviral drugs, the only current form of treatment is supportive care, i.e. relieving pain and other symptoms. What has been raising hope for developing RNA antivirals are the successes of antiviral therapy against the HCV [7]. The potent effects of these antivirals are mainly based on targeting proteases and polymerases, two of the essential viral enzymes. Basic research of these enzymes has formed the groundwork of rational drug design, enabling the development of specific molecules that bind and inhibit the enzymes. However, the action of novel synthetic molecules within the human body is rather unpredictable, leading to a high failure rate in the later stages of clinical trials. Additionally, the rapid rates of mutation further increase the overall fitness of the virus, making it resistant to antiviral agents, especially in the case of single-compound regimens. Greater antiviral effect is achieved by the combination of several antivirals, which usually include both polymerase and protease inhibitors.
A papain-like protease $\left(\mathrm{PL}^{\text {pro }}\right)$ is one of two proteases encoded by the coronavirus SARSCoV-2, the cause of the current COVID-19 pandemic. $\mathrm{PL}^{\text {pro }}$ is a deubiquitinating-like (DUBlike) enzyme which negates the host interferoninduced cellular response by cleaving the interferon-stimulated gene 15 (ISG15). ISG15 is a small di-ubiquitin-like protein which is overexpressed during viral infection and covalently attached to newly synthesized proteins to mark the viral invader. ISG15 impedes the processes of the viral replication cycle. It is thought to block the formation of new viral particles due to the steric hindrance of ISG15 molecules attached to structural proteins that form the virion $[8,9]$. Therefore, cessation of the viral defence mediated by $\mathrm{PL}^{\mathrm{pro}}$ makes it a bona fide therapeutic target. Moreover, the inhibition of the PL ${ }^{\text {pro }}$ enzyme from other coronaviruses has been demonstrated to suppress viral replication [10-12].

Tick-borne encephalitis (TBE) is the most significant flaviviral tick-borne disease that causes brain damage, paralysis and death. There are 10,000 to 12,000 reported cases of TBE each year and an increase in the worldwide risk of incidence is predicted on account of the expansion of the tick population in times of global warming and human mobility [13-15]. Other severe human pathogens in the Flavivirus genus include ZIKV, DENV, YFV, West Nile virus (WNV) and Japanese encephalitis virus (JEV). The virology and enzymology of YFV, DEVN, WNV and ZIKV have been studied extensively for the past 30 years, and several kinetic and structural studies of key enzymes are available [16-21]. Significant structural and functional similarity between proteins of a single genus make these findings transferable and instrumental in other studies [22].

TBEV polyprotein is processed into three structural proteins which form the envelope, membrane and capsid, and seven nonstructural (NS) proteins, named NS1, NS2A, NS2B, NS3, NS4A, NS4B, and NS5. NS3 possesses two distinct activities, helicase and protease activity, on N-terminus and C-terminus, respectively. NS3 protease $\left(\mathrm{NS}^{\mathrm{pro}}\right)$ is a chymotrypsin-like serine protease whose cleavage site is specified by the sequence $\mathrm{XX} \downarrow \mathrm{Y}$ where $\mathrm{X}$ is a positively charged 
residue and $\mathrm{Y}$ is a small residue such as serine or glycine [23]. NS2B anchors the NS3 to the endoplasmic reticulum by its termini, and is known to participate in the protease reaction.

Here, we report a general FRET-based method for high-throughput quantitative screening (HTS) of potential inhibitors, and for testing other enzymatic properties of viral and non-viral proteases. In addition to validating potential rationally designed molecules, HTS enables screening of already developed and clinically approved molecules that can potentially serve other purposes. As HTS plays an indispensable role in antiviral drug development, the methods must be as economical and rapid as possible while granting high reproducibility and robustness.

For our assay, we have selected common, attainable and stable fluorescent proteins. The FRET pair of our choice consisted of a fluorescence donor (eGFP) and a fluorescence acceptor (mCherry). FRET is a non-radiative transfer of energy from one fluorophore (donor) to the other chromophore (acceptor). Essentially, FRET-based assays report on the distance between the donor and the acceptor. While the fluorophores are in close proximity, the donor is excited and transfers its energy to the acceptor, which then produces a fluorescence signal at its characteristic wavelength. Upon separation, i.e. increase in the distance between the fluorophores, FRET is abolished, and the acceptor ceases to produce the signal (Figure 1). Thanks to its dependence on inverse-sixth-power distance, FRET is a remarkably sensitive tool for measuring dissociation of molecules. FRET is also influenced by an overlap between the emission spectrum of the donor and absorption spectrum of the acceptor, quantum yield of the donor, orientation between fluorophores dipoles and other physical factors of the environment [24]. The fluorescent pair can be readily changed accordingly to the needs of a particular experiment. As a proof of principle, we have selected two medicinally significant targets, the $\mathrm{PL}^{\text {pro }}$ from SARS-CoV-2 and the NS2B-NS3 protease from TBEV, and tested several small molecules to optimize and validate the assay for an array of molecules and also different classes of proteases.

\section{Results}

\section{Preparation of TBEV chymotrypsin-like protease and SARS-CoV2 papain-like protease}

The proteolytic activity of the TBEV NS3 protease is dependent on association with the NS2B cofactor. We prepared the NS2B-NS3 protease construct composed of NS2B (residues 45-96 linked with residues 116 to 131), followed by residues 1-190 of NS3 linked via a glycinerich linker (Figure S2A). This construct is similar to the constructs previously used to express other active and soluble flaviviral proteases, such as DENV [27]. The recombinant NS2B-NS3 protease was transformed and expressed in $E$. coli NiCo21 (DE3) cells and purified to homogeneity with yields of $2.4 \mathrm{mg}$ per 1 litre of E. coli culture. The junction between NS2B and NS3 was cleaved by autoproteolytic activity during the purification (Figure S2B) as it has been observed for ZIKV protease [18]. The cleavage site corresponds to the enzyme's specificity for two basic residues followed by a small residue (here Arg- Arg-Ser) which directly confirmed the in vitro enzymatic activity. PL $\mathrm{PL}^{\text {pro }}$ from SARS-CoV2 was recently recognized to facilitate specific cleavage of the di-ubiquitinlike protein ISG15 [28]. We have also produced the $\mathrm{PL}^{\text {pro }}$ protein recombinantly in E.coli and purified it to homogeneity

\section{Fluorogenic substrates for NS2B-NS3 ${ }^{\text {pro }}$ and $\mathbf{P L}^{\text {pro }}$ and optimization of activity assays}

A sequence of the substrate for the proteolytic reaction of NS2B-NS3 ${ }^{\text {pro }}$ was designed to have a natural cleavage site present between the NS2B and NS3 of TBEV, flanked by GFP and mCherry fluorescent proteins on the $\mathrm{N}$ and $\mathrm{C}$ terminus, respectively (Figure 1). This recombinant substrate was expressed in E. coli and purified to homogeneity. The fluorogenic $\mathrm{PL}^{\text {pro }}$ substrate was generated similarly as for NS2B-NS3pro, but the substrate molecule, ISG15, was cloned between the genes for the identical FRET pair (mCherry and eGFP) (Figure 1). This fusion protein was 
recombinantly expressed in E. coli and purified to homogeneity too.

The activities of both NS2B-NS3 ${ }^{\text {pro }}$ and PL $^{\text {pro }}$ were tested in vitro using small-batch reactions in physiological conditions. The results of these reactions and the subsequent activity of both proteases were validated on an SDS-PAGE based assay (Figure 1, SI Figure $5 \& 6$ ). Then, the fluorescent properties of NS2B-NS3 ${ }^{\text {pro }}$ and PL $^{\text {pro }}$ substrates were tested on a plate reader with adjustable wavelength (Tecan). In the case of FRET-based kinetics, both the increase of the donor fluorescence or decrease of the acceptor fluorescence can be followed to determine the rate of the reactions. We measured both the excitation and the emission spectra of the substrate and of the final product. This allowed us to determine the spectral conditions where the change of fluorescence was greatest upon the addition of the enzyme (Figure S3). The optimal excitation wavelength was $488 \mathrm{~nm}$ and the optimal emission wavelength was $610 \mathrm{~nm}$. These parameters were used for all the FRET measurements.

\section{Quantitative FRET assay for testing potential inhibitors of viral proteases in a high- throughput format}

With established reaction conditions for the assay, we proceeded to measure the optimal enzyme concentration to achieve steady-state kinetics in the case of $\mathrm{PL}^{\text {pro }}$, where the reaction rate is constant, and single turnover in the case of NS2B-NS3 ${ }^{\text {pro }}$. The single-turnover approach, which is done at the opposite limit to the steadystate kinetics, allowed us to rapidly investigate the inhibition of a protease which is catalytically less active. Overall, both conditions enabled the linear fit of initial reaction rates. This additionally gives sufficient time for the measurement of the reactions in a highthroughput mode in the entire plate. We tested serial dilutions of enzymes with constant amounts of the substrate. The fluorescence change and reaction rates were satisfactory when we used $1 \mu \mathrm{M}$ substrate and $20 \mathrm{nM}$ enzyme in the case for PL ${ }^{\text {pro }}$, and $0.25 \mu \mathrm{M}$ substrate and $2.5 \mu \mathrm{M}$ enzyme in the case for NS2B-NS3 ${ }^{\text {pro }}$ (Figure 1-3). The excess of NS2B-NS3 ${ }^{\text {pro }}$ over its substrate was used to compensate for the low activity of this protease in vitro and, therefore, to enable rapid screening. At a 1:1 molar ratio between the enzyme and its substrate, the reaction went to completion in 16 hours. Upon the 10-fold saturation with the enzyme, the reaction time was effectively reduced to 3.5 hours.

We selected several inhibitors of PL ${ }^{\mathrm{pro}}$ and NS2BNS$^{\text {pro }}{ }^{\text {to }}$ be tested in our FRET-based assay in the 384-well plate format. All inhibitors were dissolved close to their solubility limits to achieve the maximum range of concentrations in individual assays. Typically, we prepared inhibitors at $3 \mathrm{mM}, 10 \mathrm{mM}$ or $50 \mathrm{mM}$ concentrations and, where possible, serial dilutions of inhibitors in the reaction buffer were used. The 384-well plate layout of the reaction allowed for the following setup: two control reactions where no enzyme or inhibitor was present, twelve to sixteen different reactions with a gradient of concentration, and one control with both enzyme and substrate. In this set, the reactions were measured in three to four technical replicates, and all of the sets of these reactions were repeated at least three times. The time allowed for the proteolytic reaction was 4060 mins for $\mathrm{PL}^{\text {pro }}$, and 3.5 hours for NS2B$\mathrm{NS}^{\text {pro }}$. Our intention was the rapid measurement of the IC50 values in a broad range of concentrations. Up to 3 different inhibitors could be measured simultaneously. The assay setup was optimized such that the linear phase of the reaction would be sufficiently long to allow the mixing and measuring of the entire plate of 384wells.

\section{The quality of the assay}

The average Z' factor, the measure of the quality of the assay, for this assay was determined to be $0.49 \pm 0.09$. The average signal-to-noise (STN) ratio for $\mathrm{PL}^{\text {pro }} \mathrm{STN}=153 \pm 27$. The ratio of fluorescence of substrate and product was 1.56. The average signal-to-noise ratio for NS2BNS3 $^{\text {pro }}$ substrate was STN $=138 \pm 42$. Signal-tobackground (STB) was 54.6 for the substrate and 33.4 for the product.

\footnotetext{
Length of the glycine-rich linker between NS2Band NS3 has a minor influence on substrate conversion of NS2B-NS3 ${ }^{\text {pro }}$.
} 
To demonstrate the influence of the length of glycine-rich linker on cleavage efficiency, we prepared two other constructs of NS2B-NS3 ${ }^{\text {pro }}$ with longer (G4SG2SGSGS2GSGSG3) and shorter (G1SG3) linker. The proteolytic activity was tested in vitro with serial dilutions of the enzymes and constant amounts of the substrate. The reaction progress was analysed densitometrically from SDS-PAGE gels. Results from graphical representation show comparable cleavage efficiency for NS2B-NS3 ${ }^{\text {pro }}$ with the original, longer and shorter linker. Apparently, the proteolytic activity is influenced to a small extent (SI Figure 6).

\section{FRET-based high-throughput determines reproducible IC $_{50}$ values}

assay

Fluorogenic substrates with protease-specific cleavage sites were used to investigate the activity of the PL $^{\text {pro }}$ and NS2B-NS3 ${ }^{\text {pro }}$ and their inhibition by small molecule and peptide inhibitors. To quantitatively measure the potency of the potential inhibitors, we determined their IC50 values. The optimum concentration of enzymes and their substrates were used for all the inhibition reactions, i.e. $20 \mathrm{nM}$ enzyme and $1 \mu \mathrm{M}$ substrate, and $2.5 \mu \mathrm{M}$ enzyme and $0.25 \mu \mathrm{M}$ substrate were used for PL ${ }^{\text {pro }}$ and NS2B- NS3 ${ }^{\text {pro }}$, respectively.

\section{The potency of TBEV NS2B-NS3 ${ }^{\text {pro }}$ inhibitors}

TBEV protease has not been characterized structurally. However, it is known that the flaviviral NS2B- NS3 $3^{\text {pro }}$ is a serine protease that is highly conserved among the Flavivirus genus [22]. Therefore, we have chosen to test several commercially available inhibitors that are sufficiently soluble and their interaction with the ZIKV, DENV and WNV proteases was well characterized (DTNB, aprotinin) [17, 18, 29]. Additionally, leupeptin was picked to represent a broad-spectrum protease inhibitor [30]. The measured IC50 values are listed in SI Table 1. The dose-response curves from the FRET measurements on the Tecan microplate reader and illustrative SDS-PAGE gels are shown in Figure 2. The detailed principle of FRET-based assays and the further analysis of SDS-PAGE gel-based assay is exemplified in SI Figures 4 - 6.
In the case of leupeptin, there was no inhibition observed as confirmed by the SDS-PAGE analysis. Aprotinin (also known as bovine pancreatic inhibitor), a competitive serine protease inhibitor,inhibitstheTBEVprotease with an IC50 value of $1.8 \pm 0.2 \mu \mathrm{M}$. DTNB inhibited the flaviviral NS2B- NS3 ${ }^{\text {pro }}$ enzyme with an IC50 value of $303 \pm 54 \mu \mathrm{M}$. The DTNB molecule inhibits enzymes by forming disulfide bonds with cysteine residues on their surface. Therefore, reducing agents needed to be omitted from the reaction buffer and the enzyme stock solution (containing $\beta$-ME) was desalted to avoid premature reduction of DTNB. As expected, desalting resulted in increased instability of the enzyme and a tendency to precipitate. Rapid manipulation at low temperature was thus essential prior to the measurement.

\section{Potential SARS-CoV-2 PI ${ }^{\text {pro }}$ inhibitors, Antabuse inhibits $\mathbf{P L}^{\text {pro }}$ within the nanomolar range}

For the establishment and validity of the highthroughput character of our assay, we have selected 2- mercaptopurine (2-MP), 6mercaptopurine (6-MP), JB24, Antabuse and aprotinin (SI Figure 3), and tested them with the PL $^{\text {pro enzyme. }}$

All the reactions were tested in the same aforementioned conditions. As expected, aprotinin displayed no inhibition of the enzyme in the measured range of concentrations. We synthesized JB24 as previously described as compound number 24 [31]. This molecule inhibited PL ${ }^{\text {pro }}$ significantly with an IC50 of $1.48 \pm$ $0.39 \mu \mathrm{M}$. These two small molecules weResults

\section{Preparation of TBEV chymotrypsin-like protease and SARS-CoV2 papain-like protease}

The proteolytic activity of the TBEV NS3 protease is dependent on association with the NS2B cofactor. We prepared the NS2B-NS3 protease construct composed of NS2B (residues 45-96 linked with residues 116 to 131), followed by residues 1-190 of NS3 linked via a glycinerich linker (Figure S2A). This construct is similar to the constructs previously used to express other 
active and soluble flaviviral proteases, such as DENV [27]. The recombinant NS2B-NS3 protease was transformed and expressed in $E$. coli NiCo21 (DE3) cells and purified to homogeneity with yields of $2.4 \mathrm{mg}$ per 1 litre of E. coli culture. The junction between NS2B and NS3 was cleaved by autoproteolytic activity during the purification (Figure S2B) as it has been observed for ZIKV protease [18]. The cleavage site corresponds to the enzyme's specificity for two basic residues followed by a small residue (here Arg- Arg-Ser) which directly confirmed the in vitro enzymatic activity. PL ${ }^{\text {pro }}$ from SARS-CoV2 was recently recognized to facilitate specific cleavage of the di-ubiquitinlike protein ISG15 [28]. We have also produced the $\mathrm{PL}^{\text {pro }}$ protein recombinantly in E.coli and purified it to homogeneity

\section{Fluorogenic substrates for NS2B-NS3 ${ }^{\text {pro }}$ and $\mathbf{P L}^{\text {pro }}$ and optimization of activity assays}

A sequence of the substrate for the proteolytic reaction of NS2B-NS3 ${ }^{\text {pro }}$ was designed to have a natural cleavage site present between the NS2B and NS3 of TBEV, flanked by GFP and mCherry fluorescent proteins on the $\mathrm{N}$ and $\mathrm{C}$ terminus, respectively (Figure 1). This recombinant substrate was expressed in E. coli and purified to homogeneity. The fluorogenic PL ${ }^{\text {pro }}$ substrate was generated similarly as for NS2B-NS3pro, but the substrate molecule, ISG15, was cloned between the genes for the identical FRET pair (mCherry and eGFP) (Figure 1). This fusion protein was recombinantly expressed in E. coli and purified to homogeneity too.

The activities of both NS2B-NS3 ${ }^{\text {pro }}$ and PL $^{\text {pro }}$ were tested in vitro using small-batch reactions in physiological conditions. The results of these reactions and the subsequent activity of both proteases were validated on an SDS-PAGE based assay (Figure 1, SI Figure $5 \& 6$ ). Then, the fluorescent properties of NS2B-NS3 ${ }^{\text {pro }}$ and PL $^{\text {pro }}$ substrates were tested on a plate reader with adjustable wavelength (Tecan). In the case of FRET-based kinetics, both the increase of the donor fluorescence or decrease of the acceptor fluorescence can be followed to determine the rate of the reactions. We measured both the excitation and the emission spectra of the substrate and of the final product. This allowed us to determine the spectral conditions where the change of fluorescence was greatest upon the addition of the enzyme (Figure S3). The optimal excitation wavelength was $488 \mathrm{~nm}$ and the optimal emission wavelength was $610 \mathrm{~nm}$. These parameters were used for all the FRET measurements.

\section{Quantitative FRET assay for testing potential inhibitors of viral proteases in a high- throughput format}

With established reaction conditions for the assay, we proceeded to measure the optimal enzyme concentration to achieve steady-state kinetics in the case of $\mathrm{PL}^{\mathrm{pro}}$, where the reaction rate is constant, and single turnover in the case of NS2B-NS3 $3^{\text {pro }}$. The single-turnover approach, which is done at the opposite limit to the steadystate kinetics, allowed us to rapidly investigate the inhibition of a protease which is catalytically less active. Overall, both conditions enabled the linear fit of initial reaction rates. This additionally gives sufficient time for the measurement of the reactions in a highthroughput mode in the entire plate. We tested serial dilutions of enzymes with constant amounts of the substrate. The fluorescence change and reaction rates were satisfactory when we used $1 \mu \mathrm{M}$ substrate and $20 \mathrm{nM}$ enzyme in the case for $\mathrm{PL}^{\mathrm{pro}}$, and $0.25 \mu \mathrm{M}$ substrate and $2.5 \mu \mathrm{M}$ enzyme in the case for NS2B-NS3 ${ }^{\text {pro }}$ (Figure 1-3). The excess of NS2B-NS3 ${ }^{\text {pro }}$ over its substrate was used to compensate for the low activity of this protease in vitro and, therefore, to enable rapid screening. At a 1:1 molar ratio between the enzyme and its substrate, the reaction went to completion in 16 hours. Upon the 10-fold saturation with the enzyme, the reaction time was effectively reduced to 3.5 hours.

We selected several inhibitors of PL ${ }^{\text {pro }}$ and NS2B$\mathrm{NS}^{\text {pro }}$ to be tested in our FRET-based assay in the 384-well plate format. All inhibitors were dissolved close to their solubility limits to achieve the maximum range of concentrations in individual assays. Typically, we prepared inhibitors at $3 \mathrm{mM}, 10 \mathrm{mM}$ or $50 \mathrm{mM}$ concentrations and, where possible, serial dilutions of inhibitors in the reaction buffer were 
used. The 384-well plate layout of the reaction allowed for the following setup: two control reactions where no enzyme or inhibitor was present, twelve to sixteen different reactions with a gradient of concentration, and one control with both enzyme and substrate. In this set, the reactions were measured in three to four technical replicates, and all of the sets of these reactions were repeated at least three times. The time allowed for the proteolytic reaction was 4060 mins for PL $^{\text {pro, }}$ and 3.5 hours for NS2B$\mathrm{NS}^{\text {pro }}$. Our intention was the rapid measurement of the IC50 values in a broad range of concentrations. Up to 3 different inhibitors could be measured simultaneously. The assay setup was optimized such that the linear phase of the reaction would be sufficiently long to allow the mixing and measuring of the entire plate of 384wells.

\section{The quality of the assay}

The average Z' factor, the measure of the quality of the assay, for this assay was determined to be $0.49 \pm 0.09$. The average signal-to-noise (STN) ratio for PL $^{\text {pro }}$ STN $=153 \pm 27$. The ratio of fluorescence of substrate and product was 1.56. The average signal-to-noise ratio for NS2B$\mathrm{NS}^{\text {pro }}$ substrate was STN $=138 \pm 42$. Signal-tobackground (STB) was 54.6 for the substrate and 33.4 for the product.

\section{Length of the glycine-rich linker between NS2Band NS3 has a minor influence on substrate conversion of NS2B-NS3 ${ }^{\text {pro }}$.}

To demonstrate the influence of the length of glycine-rich linker on cleavage efficiency, we prepared two other constructs of NS2B-NS3 ${ }^{\text {pro }}$ with longer (G4SG2SGSGS2GSGSG3) and shorter (G1SG3) linker. The proteolytic activity was tested in vitro with serial dilutions of the enzymes and constant amounts of the substrate. The reaction progress was analysed densitometrically from SDS-PAGE gels. Results from graphical representation show comparable cleavage efficiency for NS2B-NS3 ${ }^{\text {pro }}$ with the original, longer and shorter linker. Apparently, the proteolytic activity is influenced to a small extent (SI Figure 6).

\section{FRET-based high-throughput assay determines reproducible $\mathrm{IC}_{50}$ values}

Fluorogenic substrates with protease-specific cleavage sites were used to investigate the activity of the PL ${ }^{\text {pro }}$ and NS2B-NS3 ${ }^{\text {pro }}$ and their inhibition by small molecule and peptide inhibitors. To quantitatively measure the potency of the potential inhibitors, we determined their IC50 values. The optimum concentration of enzymes and their substrates were used for all the inhibition reactions, i.e. $20 \mathrm{nM}$ enzyme and $1 \mu \mathrm{M}$ substrate, and $2.5 \mu \mathrm{M}$ enzyme and $0.25 \mu \mathrm{M}$ substrate were used for PL ${ }^{\text {pro }}$ and NS2B- NS3 ${ }^{\text {pro }}$, respectively.

\section{The potency of TBEV NS2B-NS3 ${ }^{\text {pro }}$ inhibitors}

TBEV protease has not been characterized structurally. However, it is known that the flaviviral NS2B- NS3 ${ }^{\text {pro }}$ is a serine protease that is highly conserved among the Flavivirus genus [22]. Therefore, we have chosen to test several commercially available inhibitors that are sufficiently soluble and their interaction with the ZIKV, DENV and WNV proteases was well characterized (DTNB, aprotinin) [17, 18, 29]. Additionally, leupeptin was picked to represent a broad-spectrum protease inhibitor [30]. The measured IC50 values are listed in SI Table 1. The dose-response curves from the FRET measurements on the Tecan microplate reader and illustrative SDS-PAGE gels are shown in Figure 2. The detailed principle of FRET-based assays and the further analysis of SDS-PAGE gel-based assay is exemplified in SI Figures 4 - 6.

In the case of leupeptin, there was no inhibition observed as confirmed by the SDS-PAGE analysis. Aprotinin (also known as bovine pancreatic inhibitor), a competitive serine protease inhibitor,inhibitstheTBEVprotease with an IC50 value of $1.8 \pm 0.2 \mu \mathrm{M}$. DTNB inhibited the flaviviral NS2B- NS3 ${ }^{\text {pro }}$ enzyme with an IC50 value of $303 \pm 54 \mu \mathrm{M}$. The DTNB molecule inhibits enzymes by forming disulfide bonds with cysteine residues on their surface. Therefore, reducing agents needed to be omitted from the reaction buffer and the enzyme stock solution (containing $\beta$-ME) was desalted to avoid premature reduction of DTNB. As expected, 
desalting resulted in increased instability of the enzyme and a tendency to precipitate. Rapid manipulation at low temperature was thus essential prior to the measurement.

\section{Potential SARS-CoV-2 PI ${ }^{\text {pro }}$ inhibitors, Antabuse inhibits PL $^{\text {pro }}$ within the nanomolar range}

For the establishment and validity of the highthroughput character of our assay, we have selected 2- mercaptopurine (2-MP), 6mercaptopurine (6-MP), JB24, Antabuse and aprotinin (SI Figure 3), and tested them with the $\mathrm{PL}^{\text {pro }}$ enzyme.

All the reactions were tested in the same aforementioned conditions. As expected, aprotinin displayed no inhibition of the enzyme in the measured range of concentrations. We synthesized JB24 as previously described as compound number 24 [31]. This molecule inhibited PL ${ }^{\text {pro }}$ significantly with an IC50 of $1.48 \pm$ $0.39 \mu \mathrm{M}$. These two small molecules were utilized during the optimization of the assay. The results were reproducible as individual titrations were measured with different batches of defrosted and newly diluted enzyme and a substrate (Figure 3).

Next, Antabuse, 2-MP and 6-MP were tested in order to measure their inhibition properties on $\mathrm{PL}^{\mathrm{pro}}$. The inhibition of these compounds is sensitive to reducing agents. Therefore, the reducing agent had to be omitted from the reactions. It is noteworthy that even in the presence of a reducing agent only in the stock solution of substrate and enzyme, it influenced the IC50 values of these compounds [32]. Therefore, it had to be removed from the reaction by desalting. Antabuse inhibition was $80 \pm 38$ $\mathrm{nM}$ in the absence of DTT or $\beta$-ME. Interestingly, only 2-MP but not 6-MP had an inhibitory effect on $\mathrm{PL}^{\text {pro }}\left(\mathrm{IC}_{50}=0.82 \pm 0.6 \mu \mathrm{M}\right)$. 2-MP inhibition was also diminished by the presence of DTT in the reaction buffer.

\section{Discussion}

The assay presented in this study offers a rapid, inexpensive and sensitive high-throughput screening of protease inhibitors. We demonstrate its effectivity and robustness on two viral proteases which differ both in specificity and activity. Both proteases represent significant therapeutic targets. The protease from SARS$\mathrm{CoV}-2$, a papain-like protease $\left(\mathrm{PL}^{\mathrm{pro}}\right)$, is a relatively fast-acting enzyme which prevents cellular antiviral response by its DUB activity. The second protease, formed by the nonstructural proteins 2B and 3 (NS2B-NS3 ${ }^{\text {pro }}$ ), from the tickborne encephalitis virus (TBEV) processes newly synthesized TBEV polyprotein during viral infection and displays low catalytic activity in vitro. The proteolytic reactions performed in vitro are significantly slower than the proteolytical cleavage in infected cells especially in the case of the TBEV protease, however, to the results are accurate and enable to establish an IC50 value for each inhibitor tested which is the main starting point for drug design.

To validate the assay quantitatively, we obtained reproducible values of the half-maximal inhibitory concentration (IC50). Aprotinin (also known as the bovine pancreatic inhibitor) inhibited NS2B-NS3 ${ }^{\text {pro }}$ with an IC50 of $1.8 \pm 0.2$ $\mu \mathrm{M}$ at an enzyme concentration of $2.5 \mu \mathrm{M}$. Notably, this protease is inhibited significantly less efficiently than other proteases of Flaviviruses. For instance, the WNF protease displayed an IC50 of $20 \mathrm{nM}$ when the enzyme concentration was $10 \mathrm{nM}$ [33], and the DENV protease displayed an IC50 of $65 \mathrm{nM}$ when the enzyme concentration was $1 \mu \mathrm{M}$ [34]. The assay presented here can reveal compounds inhibiting the viral proteases in vitro. Nevertheless, these must be tested in cell-based assays to validate their potency.

We have demonstrated the versatility of this assay and that the fluorogenic substrate can be prepared easily by recombinant expression in $E$. coli. Moreover, the recombinant character of the substrate broadens the area for the assessment to practically any protease from any source from viruses to humans. In the case of our assay, eGFP and mCherry have been used for several reasons. The genes of these molecules are readily available in most laboratories. The excitation maximum of eGFP is in the vicinity of one of the most commonly used lasers (argon laser, 488 $\mathrm{nm}$ ), which is available on most instruments. Our 
assays with enzymes from very distinct kinetics have demonstrated the practicality of our choice of the FRET pair (eGFP and mCherry) in combination within the gel-based assays. Both eGFP and mCherry are very stable proteins with sufficiently good FRET efficiency for the assay. In the case of further revalidation in the PAGE gel, the larger spectral differences are advantageous. Importantly, for enhanced sensitivity of this type of assay, other FRET pairs such as the CyPet-YPet pair could be considered. This pair offers greater FRET emission gains, especially when instrumental setup allows for excitation at $414 \mathrm{~nm}$ and the collection of emissions at $530 \mathrm{~nm}$ [35].

In comparison with radioisotope-based methods, the fluorescence-based methods are safe to use, easy to operate, and the measurements and possible evaluation are carried out in real-time. In most cases, our fluorescent assay does not require further manipulation and analysis of the sample, e.g. separation of reactants from products and measurements. On the other hand, interference from other components of the assay may be an issue in case of fluorescent assays and has to be taken into consideration. These components may interfere with the assay by altering the amount of fluorescent signal and decreasing the sensitivity of the assay. In the proper set-up of our assay, the photobleaching of the components can be corrected for by running the controls for the assay, e.g. fluorescent substrate without the enzyme. It is noteworthy that the fluorescent substrate, cofactors or inhibitors may interfere with the assay in such a way that FRET-based results are not suitable for evaluation. In such a case, assays can be resolved on a PAGE gel, with the cost of a lower throughput.

The fluorescent assay using SDS-PAGE gel demonstrated in this work represents reaction progress at the last time point of the reaction where the reaction was stopped by the SDS sample buffer (Figure $2 \& 3$, SI Figures $5 \& 6$ ). The amount of the substrate cleaved corresponds to the appearance of the product band, the thinning of the substrate band becomes apparent only in a later stage of the reaction therefore the densitometric analysis is necessary to evaluate these experiments. The analysed gel-based data were fitted dose-response and estimated $\mathrm{IC}_{50}$ values correspond relatively well to FRET measurements confirming to validity of this FRET-based assay. These $\mathrm{IC}_{50}$ values are not to be directly compared with more precise FRET measurements determined from initial rates of the reaction. Such a comparison is only shown illustratively in SI Figure 5B,5D. All of the gelbased assays were only meant to validate the inhibition our approach and FRET-based HTS assay. We have also demonstrated the utility of SDS-PAGE gel-based fluorescent method as an alternative technique when FRET-based experiment cannot be used.

Other fluorescent techniques besides FRET-based methods may be considered to be applicable for measurements of the rate of proteolysis, especially in similar sample setups where the large fluorescent substrate is proteolytically cleaved to one or several small fluorescent molecules. In this case, fluorescence anisotropy or polarisation (FA/FP), homogeneous timeresolved fluorescence (HTRF), and fluorescence correlation spectroscopy (FCS) are among these options. There are advantages and disadvantages to all of these methods, however, there is one key aspect that outweighs these excellent techniques in favour of FRET-based techniques and that is its suitability for the HTS.

The recent advances in FCS allow measurements in high-throughput mode, but the instrument cost, complex evaluation and speed in processing of the samples may be a major obstacle in the use of such a method [36]. On the other hand, when the number of available components is limited and there are low volumes of the sample, confocal microscopy may be favourable. Although FP and HTRF methods can be also used in highthroughput screening (HTS), they require more complex instrumentation and evaluation of the results. In this case, low cost and greater versatility, modality and possibly greater sensitivity favour the FRET-based method [37].

The other fluorescent-based methods have plenty of advantages, but one of the overwhelming factors in favour of this assay is its low cost and versatility of preparation. This assay can be easily performed in a typical laboratory and only requires a fluorescent plate reader. The fluorescent parameters of the substrate may be 
tailored to suit the available instruments of a particular researcher and to the given application, e.g. mutagenic study of the variability of the substrate or testing the enzyme kinetics. Since the substrate is recombinant, it avoids costly synthesis of specific substrates with synthetic fluorescent probes that might be essential for the aforementioned methods. Fluorescence assays typically offer the best balance between cost and sensitivity in high-throughput screening (HTS) experiments.

Rapid response to threats posed by viral pathogens is and will clearly continue to be one of the most important challenges for our globalized society. This response is associated with our ability to quickly design and prepare new antivirals that will be able to affect these pathogens at their weakest points. Experience with the discovery of drugs against both HIV and HCV illustrates that viral proteases are important drug targets. Here, we have shown that it is possible to quickly and efficiently develop an assay against various viral proteases and convert it to the HTS format. Therefore, the assay developed here is a very useful tool for early drug discovery and can be quickly designed and used for both drug repurposing and the identification of completely new protease inhibitors in fight against various viral pathogens.

\section{Experimental procedures}

\section{Cloning, expression and purification of the recombinant NS2B-NS3 ${ }^{\text {pro }}$ and PL $^{\text {pro }}$}

The DNA sequence encoding the TBEV NS2BNS3 $^{\text {pro }}$ enzyme (strain Hypr; GeneBank: KP716978.1) was commercially synthesized (Invitrogen) and encoded NS2B (residues 45-96), a GGGGSGGGG linker and NS3 (residues 116131) followed by a 6xHis-tag. The NS2B-NS3pro encoding gene was cloned into the NcoI and the NotI sites of pRSFD vector (Novagen). The vector was transformed into Escherichia coli $(E$. coli) NiCo21 (DE3) cells and cultured in LB medium with $40 \mu \mathrm{g} / \mathrm{ml}$ of kanamycin. The culture was left to shake overnight at $37{ }^{\circ} \mathrm{C}$ and then used to inoculate ZY5052 autoinduction media. After reaching an optical density of 0.60.8 (OD600) at $37{ }^{\circ} \mathrm{C}$, the temperature was lowered to $18{ }^{\circ} \mathrm{C}$ and the culture was grown overnight. The cells were lysed by sonication in a lysis buffer containing $20 \mathrm{mM}$ Tris- $\mathrm{HCl} \mathrm{pH}=8$; $300 \mathrm{mM} \mathrm{NaCl} ; 20 \mathrm{mM}$ imidazole; $10 \%$ glycerol and $3 \mathrm{mM} \beta$ - mercaptoethanol ( $\beta$-ME). The supernatant was separated by centrifugation, incubated with $2 \mathrm{ml}$ of Ni- NTA resin (MacheryNagel) and extensively washed with the lysis buffer using the batch technique. The slurry was loaded on the column and the protein was eluted with the lysis buffer supplemented with $300 \mathrm{mM}$ imidazole $\mathrm{pH}=8.0$. The eluate was further purified using the size-exclusion Superdex 75 HiLoad 16/600 column (GE Healthcare) with a gel filtration buffer $(20 \mathrm{mM}$ Tris- $\mathrm{HCl} \mathrm{pH}=8$; $300 \mathrm{mM} \mathrm{NaCl} ; 10 \%$ glycerol and $3 \mathrm{mM} \beta-\mathrm{ME}$ ). Protein was desalted on a HiPrep 26/10 desalting column (GE Healthcare) and loaded on an anionexchange HiTrap Q HP column. The protein was eluted by a salt gradient in buffer A (20 mM Tris$\mathrm{HCl} \mathrm{pH}=8,50 \mathrm{mM} \mathrm{NaCl} 10 \%$ glycerol and 3 $\mathrm{mM} \beta-\mathrm{ME})$. The purity of the protein was verified on SDS-PAGE in 15\% acrylamide:bisacrylamide gel, stained with Coomassie brilliant blue (SI Figure 2). The protein was concentrated to $2.8 \mathrm{mg} / \mathrm{ml}$ frozen in $\mathrm{N}_{2}(\mathrm{l})$ and kept at $-80{ }^{\circ} \mathrm{C}$.

The gene encoding the $\mathrm{PL}^{\text {pro }}$ (also known as nsp3) protein from SARS-CoV-2 (YP_009725299.1) was also synthesized commercially (Invitrogen) and cloned into the pSUMO1 vector with $\mathrm{N}$ terminal 8xHis conjugated with yeast SUMO, forming a fusion solubility/affinity tag. The plasmid was transformed into E. coli NiCo21 (DE3) and expressed in ZY5052 autoinduction media supplemented with $50 \mu \mathrm{M} \mathrm{ZnSO}_{4}$ and affinity-purified identically as the NS2B-NS3 ${ }^{\text {pro }}$. The protein was desalted on a HiPrep 26/10 desalting column (GE Healthcare) and loaded on an anion-exchange HiTrap Q HP column (GE Healthcare). Next, the 8xHis-SUMO-tag was cleaved using SUMO protease from yeast (Ulp1), and after overnight incubation at $4^{\circ} \mathrm{C}$, the sample was loaded onto a HisTrap HP, equilibrated in a lysis buffer. Unbound fractions containing $\mathrm{PL}^{\text {pro }}$ were pooled, concentrated and loaded on a Superdex 75 HiLoad 16/600 column (GE Healthcare) equilibrated with $20 \mathrm{mM}$ Tris- $\mathrm{HCl}$ $\mathrm{pH}=7,4 ; 50 \mathrm{mM} \mathrm{NaCl} ; 10 \%$ glycerol and $3 \mathrm{mM}$ $\beta$-ME. The protein was checked on $15 \%$ SDS PAGE gel (SI Figure 2), concentrated, and frozen in $\mathrm{N}_{2}(\mathrm{l})$ and kept at $-80{ }^{\circ} \mathrm{C}$. 
Preparation of fluorescent substrates eGFPRSSRRSDLVFS-mCherry and mCherry-ISG15- eGFP

A substrate for the proteolytic reaction of NS2BNS3 $^{\text {pro }}$ was designed to have a sequence (RSSRRSDLVFS) derived from a cleavage site present between the NS2B and NS3 of TBEV, flanked by GFP and mCherry fluorophores resulting in a plasmid encoding for GFPRSSRRSDLVFS-mCherry. The plasmid was prepared by restriction cloning. First, a gene encoding for GFP was cloned in the pHis2 vector. In the second step, the NS2B-NS3 ${ }^{\text {pro }}$ site and mCherry were added. The plasmid was transformed into the E. coli NiCo21 (DE3), and the protein was expressed in LB medium supplemented with $0.1 \mu \mathrm{g} / \mathrm{ml}$ of ampicillin, 10 $\mu \mathrm{M} \mathrm{ZnSO}_{4}, 1 \mathrm{mM}$ of $\mathrm{MgCl}_{2}$ and $\mathrm{MgSO}_{4}, 0.25$ $\mathrm{mM} \mathrm{KCl}$, and $15 \mu \mathrm{M} \mathrm{FeCl}_{2}$ dissolved in citric acid. The media was incubated in a shaker at 37 ${ }^{\circ} \mathrm{C}$. After reaching an $\mathrm{OD} 600$ of 0.4 , the temperature was lowered to $25^{\circ} \mathrm{C}$, at which 0.3 $\mu \mathrm{M}$ IPTG was added to initiate the expression. The temperature was immediately lowered to 18 ${ }^{\circ} \mathrm{C}$, and the culture was grown overnight. The purification steps were similar to those used to produce the NS2B-NS3 $3^{\text {pro }}$. The cells were briefly lysed by sonication in a lysis buffer (20 mM Tris$\mathrm{HCl} \mathrm{pH}=8 ; 300 \mathrm{mM} \mathrm{NaCl} ; 20 \mathrm{mM}$ imidazole; $10 \%(\mathrm{v} / \mathrm{v})$ glycerol and $3 \mathrm{mM} \beta-\mathrm{ME})$, and then supplemented with one tablet/l of the complete mini EDTA- free protease inhibitor cocktail. The supernatant was purified in a Ni-NTA column, Superdex 75 HiLoad 16/600 column, HiPrep 26/10 desalting column, and HiTrap Q HP column, respectively, using the same buffers and procedures as described above. Additionally, $\mathrm{NaCl}$ was added to a final concentration of 800 $\mathrm{mM}$ and the protein was further purified on the Superdex 75 HiLoad 16/600 column. The enzyme stored in $-80^{\circ} \mathrm{C}$.

Human ISG15 is the substrate of SARS-CoV-2 $\mathrm{PL}^{\text {pro }}$. The gene encoding ISG15 was subcloned in between genes encoding the FRET pair consisting of mCherry and eGFP (Figure 1A). All these components were amplified using PCR, and they were cloned into the plasmid pET-24a using a Gibson assembly [25]. The plasmid was transformed into $E$. coli NiCo21 (DE3), expressed and purified to homogeneity. The final recombinant protein used for the assays contained an N-terminal 6 x His-Tag, mCherry, a cleavage site for TEV protease, ISG15 and eGFP (mCherry-ISG15-eGFP). The TEV site was included for validation and versatility of the substrate.

\section{FRET-based assays of the NS2B-NS3 ${ }^{\text {pro }}$ and PL $^{\text {pro }}$ activity and inhibition}

The reactions of the proteases and their FRET substrates were performed in $80 \mu$ l in black 384well plates. In the case of NS2B-NS3 ${ }^{\text {pro }}$ reactions, there was a $2.5 \mu \mathrm{M}$ protease and $0.25 \mu \mathrm{M}$ substrate. In the case of the $\mathrm{PL}^{\text {pro }}$ reaction, there was $20 \mathrm{nM}$ protease and $1 \mu \mathrm{M}$ substrate. The reaction buffer contained $20 \mathrm{mM}$ Tris- $\mathrm{HCl} \mathrm{pH}=$ 7, $10 \mathrm{mM} \mathrm{NaCl}, 3 \mathrm{mM} \beta$-ME for NS2B-NS3 ${ }^{\text {pro }}$ or $20 \mathrm{mM}$ Tris- $\mathrm{HCl} \mathrm{pH}=7.4,50 \mathrm{mM} \mathrm{NaCl}, 10 \%$ Glycerol, $3 \mathrm{mM} \beta-\mathrm{ME}$ for $\mathrm{PL}^{\mathrm{pro}}$. The reaction conditions were optimized to fulfil the HTS character. In the case of the inhibitor 5,5-dithiobis-(2-nitrobenzoic acid) (DTNB), $\beta$-ME was omitted from the buffer due to the easy reduction of DTNB to 2-nitro-5-thiobenzoate (TNB). Similarly, $\beta$-ME was omitted in the cases of 2MP, 6-MP and Antabuse. The enzyme stock solution was desalted using the MicroSpin G-25 columns (Cytiva) when testing the easily reduced inhibitors. The titration series of the inhibitor was performed in a mixture containing a constant concentration of the substrate. Reactions were initiated by mixing equal volumes (i.e. $40 \mu \mathrm{l}$ ) of the mixture containing the substrate and inhibitor with a mixture containing the enzyme. In the reaction set up for every array of eight to twelve reactions, one positive control and one negative control were measured. Negative control only contained the FRET substrate, otherwise treated identically to other reactions. The data from negative control were used to subtract the fluorescence changes from the other datasets in order to compensate for other processes eg photobleaching. Positive control contained both the FRET substrate and the enzyme, without an inhibitor. This control was used to determine the maximum activity of the enzyme in the particular reaction set. The data were normalized to express the percentage of inhibition according to the difference between positive and negative control. Each measurement was carried out in technical triplicates. Each measurement was replicated at 
least three times. Measurements were performed using the Tecan microplate reader at $25^{\circ} \mathrm{C}$ for 3.5 hours (NS2B-NS3 ${ }^{\text {pro }}$ ) or $40-60$ mins $\left(\mathrm{PL}^{\mathrm{pro}}\right)$. To prevent the NS2B-NS3 ${ }^{\text {pro }}$ reaction mixture from evaporating, the plates were covered with a transparent Crystal Clear Sealing tape (Hampton research).

In the reaction, the decreasing fluorescence (FRET) intensity of mCherry was monitored at an emission wavelength of $610 \mathrm{~nm}$. The time interval between measurements was $30 \mathrm{~min}$ in the case of NS2B-NS3 ${ }^{\text {pro }}$ and $30 \mathrm{~s}$ to $60 \mathrm{~s}$ in the case of $\mathrm{PL}^{\text {pro }}$. The excitation wavelength was 488 $\mathrm{nm}$, with a $5 \mathrm{~nm}$ bandwidth for both slits. The lag time was zero, the integration time was $20 \mu \mathrm{s}$, and the settle time was $10 \mathrm{~ms}$ for $400 \mathrm{~Hz}$ of flash frequency. An optimal $96 \%$ gain was calculated in every measurement. A Z-position was set at $20000 \mu \mathrm{m}$ height. For each time point, 10 flashes were integrated and combined with the multiple reads per well with $100 \mu \mathrm{m}$ offset from the border of the well. Immediately after the measurement, 20 $\mu \mathrm{l}$ of $5 \mathrm{x}$ SDS sample buffer (60 $\mathrm{mM}$ Tris pH 6,8, $25 \%$ (v/v) Glycerol, 2,9 \% (w/w) SDS, 0,1 \% (v/v) Bromphenol Blue, 714 $\mathrm{mM} \beta$-ME l) was added to terminate the reaction and validate the progress on the $15 \%$ reducing SDS-PAGE.

\section{Analysis of reaction progress by gel-based assay}

The SDS-PAGE gels with resolved reaction mixtures were scanned on the Typhoon Biomolecular Imager (GE Healthcare), with a green laser $(532 \mathrm{~nm})$ and long pass red filter (LPR $660 \mathrm{~nm}$ ) were used. The images were quantified using ImageQuant TL. Lines were selected manually and the background subtraction was performed using Rolling Ball method. Bands with constant dimensions encompassing substrate and product were selected manually. The resulting substrate conversion was used in a similar manner as for fluorescent assays. The percentage of the inhibition of individual reactions was calculated relative to the control without the inhibitor. The exemplar evaluation of several gels is demonstrated in SI Figure 5 \& 6 .

\section{Determination of $Z$ ' factor and signal-to-noise ratio}

The $Z$ ' factor is a measure of the quantity of the assay for HTS. To determine the Z' factor, 24 replicates of positive control and negative control were measured under the same conditions as in the inhibition measurements. Therefore, the reactions were performed in $80 \mu \mathrm{l}$ in black 384well plates, at $25^{\circ} \mathrm{C}$, and for the appropriate time. Measurements with NS2B-NS3 $3^{\text {pro }}$ took 3.5 hours and 60 min for $\mathrm{PL}^{\text {pro. }}$. In the positive control, there was $2.5 \mu \mathrm{M}$ protease and $0.25 \mu \mathrm{M}$ substrate in the case of NS2B-NS3 $3^{\text {pro }}$, and $20 \mathrm{nM}$ protease and 1 $\mu \mathrm{M}$ substrate in the case of the $\mathrm{PL}^{\text {pro }}$. The negative control contained the same amount of substrate and no enzyme. The measurements were performed three times. The Z' factor was calculated according to the method described who defined Z' factor as:

$$
Z^{\prime} \text { factor }=1-\frac{3 \sigma_{P}-3 \sigma_{N}}{\left|\mu_{P}-\mu_{N}\right|}
$$

where $\sigma_{\mathrm{P}}$ and $\sigma_{\mathrm{N}}$ are the standard deviations of positive and negative control, respectively, and $\mu_{\mathrm{P}}$ and $\mu_{\mathrm{N}}$ are the means of positive and negative controls, respectively [26]. Signal-to-noise ratio (S/N or STN) was calculated by the ratio of the average signal over the standard deviation of the measured signal, the average STN was calculated from three different and independent measurements. Signal to background $(\mathrm{S} / \mathrm{N}$ or STB) was calculated from the average signal at $610 \mathrm{~nm}$ to average background at $750 \mathrm{~nm}$. STB and values were determined for the substrate and the product (SI Figure 2).

\section{Determination of the inhibitor potency}

To quantify the inhibitory effect of the tested molecules, we determined the half-maximal inhibitory concentration (IC50) from the measured data. The rate of the reaction was estimated from the slope of the initial part of the reaction as the decline of relative emission intensity in time (3.5 hours for NS2B-NS3 ${ }^{\text {pro }}$ measured in $30 \mathrm{~min}$ intervals) (Figure 1, SI Figure 4). For PL ${ }^{\text {pro }}, 40-$ 60 min reactions were measured in $30 \mathrm{~s}-60 \mathrm{~s}$ intervals and the slope was estimated from the 
initial 15 mins. The average slope of the negative control (no enzyme added to the substrate reaction mix) that represented the FRET signal alone was subtracted from each slope of inhibition reactions and the positive control (SI Figure 4 ). The rate of the positive control corresponded to maximal enzymatic activity. The relative percentage of the inhibition was calculated using corrected positive controls (SI Figure 4 ). All normalized data were plotted and fitted against the log of the concentration of the inhibitor to give an $\mathrm{IC}_{50}$ curve of the specific inhibitor.

Influence of length of the glycine-rich linker between NS2B and NS3

Two additional NS2B-NS3 ${ }^{\text {pro }}$ constructs with different length of the peptide linker between
NS2B and NS3 chains were prepared (longer linker $\mathrm{G}_{4} \mathrm{SG}_{2} \mathrm{SGSGS}_{2} \mathrm{GSGSG}_{3}$ and shorter linker $\mathrm{G}_{1} \mathrm{SG}_{3}$ ). These constructs were used to perform reactions with NS2B-NS3 FRET substrates as described above. Briefly, the titration series contained 0,063 to $4 \mu \mathrm{M}$ enzyme and constant concentration of the substrate, $0,25 \mu \mathrm{M}$. The reaction buffer contained $20 \mathrm{mM}$ Tris- $\mathrm{HCl} \mathrm{pH}=$ 7, $10 \mathrm{mM} \mathrm{NaCl}, 3 \mathrm{mM} \beta$-ME. Reactions were performed in triplicates at $25^{\circ} \mathrm{C}$ in $80 \mu \mathrm{l}$ in the dark. After 6 hours reactions were terminated with $5 x$ SDS sample buffer and the reactions resolved on SDS-PAGE. The gel was scanned, using a laser at $532 \mathrm{~nm}$ and filter at $660 \mathrm{~nm}$ on the Amersham Typhoon Biomolecular Imager (GE Healthcare). The gels were analysed using the commercial ImageQuant TL software as described above in the section SDS-PAGE analysis. 


\section{Data availability}

All data are contained within the manuscript and supporting information.

\section{Acknowledgements}

The work was supported by the European Regional Development Fund; OP RDE; Project: "Chemical biology for drugging undruggable targets (ChemBioDrug)" (No. CZ.02.1.01/0.0/0.0/16_019/0000729). The Academy of Sciences of the Czech Republic (RVO: 61388963) is also acknowledged. We are grateful to Tamara Jenkins for critical reading of the manuscript.

\section{Author Contributions}

$B C$ and $A H$ has contributed equally to this work. $B C, A H, J B$, and JS performed experiments. $E B$ designed the study, RN, EB and JS supervised the study. BC, EB and JS wrote the manuscript.

\section{Conflicts of Interest}

The authors declare no conflict of interest.

\section{References}

1. Woolhouse, M.E.J. and L. Brierley, Epidemiological characteristics of humaninfective RNA viruses. Sci Data, 2018. 5: p. 180017.

2. Wolf, Y.I., D. Kazlauskas, J. Iranzo, A. Lucia-Sanz, J.H. Kuhn, M. Krupovic, V.V. Dolja, and E.V. Koonin, Origins and Evolution of the Global RNA Virome. mBio, 2018. 9(6).

3. Domingo, E. and J.J. Holland, RNA virus mutations and fitness for survival. Annu Rev Microbiol, 1997. 51: p. 151-78.

4. Bentley, K. and D.J. Evans, Mechanisms and consequences of positive-strand RNA virus recombination. J Gen Virol, 2018. 99(10): p. 1345-1356.

5. Rosenberg, R., Detecting the emergence of novel, zoonotic viruses pathogenic to humans. Cell Mol Life Sci, 2015. 72(6): p. 1115-25.

6. Holmes, E.C., The evolutionary genetics of emerging viruses. Annu. Rev. Ecol. Evol. Syst., 2009. 40: p. 353-372.

7. De Clercq, E., Strategies in the design of antiviral drugs. Nat Rev Drug Discov, 2002. 1(1): p. 13-25.

8. Dzimianski, J.V., F.E.M. Scholte, E. Bergeron, and S.D. Pegan, ISG15: It's Complicated. J Mol Biol, 2019. 431(21): p. 4203-4216.

9. Perng, Y.C. and D.J. Lenschow, ISG15 in antiviral immunity and beyond. Nat Rev Microbiol, 2018. 16(7): p. 423-439. 
10. Devaraj, S.G., N. Wang, Z. Chen, Z. Chen, M. Tseng, N. Barretto, R. Lin, C.J. Peters, C.T. Tseng, S.C. Baker, and K. Li, Regulation of IRF-3-dependent innate immunity by the papain-like protease domain of the severe acute respiratory syndrome coronavirus. J Biol Chem, 2007. 282(44): p. 32208-21.

11. Bailey-Elkin, B.A., R.C. Knaap, G.G. Johnson, T.J. Dalebout, D.K. Ninaber, P.B. van Kasteren, P.J. Bredenbeek, E.J. Snijder, M. Kikkert, and B.L. Mark, Crystal structure of the Middle East respiratory syndrome coronavirus (MERS-CoV) papain-like protease bound to ubiquitin facilitates targeted disruption of deubiquitinating activity to demonstrate its role in innate immune suppression. $\mathrm{J}$ Biol Chem, 2014. 289(50): p. 34667-82.

12. Ratia, K., S. Pegan, J. Takayama, K. Sleeman, M. Coughlin, S. Baliji, R. Chaudhuri, W. Fu, B.S. Prabhakar, M.E. Johnson, S.C. Baker, A.K. Ghosh, and A.D. Mesecar, A noncovalent class of papain-like protease/deubiquitinase inhibitors blocks SARS virus replication. Proc Natl Acad Sci U S A, 2008. 105(42): p. 16119-24.

13. Ruzek, D., T. Avsic Zupanc, J. Borde, A. Chrdle, L. Eyer, G. Karganova, I. Kholodilov, N. Knap, L. Kozlovskaya, A. Matveev, A.D. Miller, D.I. Osolodkin, A.K. Overby, N. Tikunova, S. Tkachev, and J. Zajkowska, Tick-borne encephalitis in Europe and Russia: Review of pathogenesis, clinical features, therapy, and vaccines. Antiviral Res, 2019. 164: p. 23-51.

14. Piesman, J. and L. Eisen, Prevention of tick-borne diseases. Annu Rev Entomol, 2008. 53: p. 323-43.

15. Pfeffer, M. and G. Dobler, Emergence of zoonotic arboviruses by animal trade and migration. Parasit Vectors, 2010. 3(1): p. 35.

16. Dubankova, A. and E. Boura, Structure of the yellow fever NS5 protein reveals conserved drug targets shared among flaviviruses. Antiviral Res, 2019. 169: p. 104536.

17. Erbel, P., N. Schiering, A. D'Arcy, M. Renatus, M. Kroemer, S.P. Lim, Z. Yin, T.H. Keller, S.G. Vasudevan, and U. Hommel, Structural basis for the activation of flaviviral NS3 proteases from dengue and West Nile virus. Nat Struct Mol Biol, 2006. 13(4): p. 372-3.

18. Phoo, W.W., Y. Li, Z. Zhang, M.Y. Lee, Y.R. Loh, Y.B. Tan, E.Y. Ng, J. Lescar, C. Kang, and D. Luo, Structure of the NS2B-NS3 protease from Zika virus after selfcleavage. Nat Commun, 2016. 7: p. 13410.

19. Hercik, K., J. Brynda, R. Nencka, and E. Boura, Structural basis of Zika virus methyltransferase inhibition by sinefungin. Arch Virol, 2017. 162(7): p. 20912096.

20. Hercik, K., J. Kozak, M. Sala, M. Dejmek, H. Hrebabecky, E. Zbornikova, M. Smola, D. Ruzek, R. Nencka, and E. Boura, Adenosine triphosphate analogs can efficiently inhibit the Zika virus RNA-dependent RNA polymerase. Antiviral Res, 2017. 137: p. 131-133. 
21. Konkolova, E., M. Dejmek, H. Hrebabecky, M. Sala, J. Boserle, R. Nencka, and E. Boura, Remdesivir triphosphate can efficiently inhibit the RNA-dependent RNA polymerase from various flaviviruses. Antiviral Res, 2020. 182: p. 104899.

22. da Fonseca, N.J., Jr., M.Q. Lima Afonso, N.G. Pedersolli, L.C. de Oliveira, D.S. Andrade, and L. Bleicher, Sequence, structure and function relationships in flaviviruses as assessed by evolutive aspects of its conserved non-structural protein domains. Biochem Biophys Res Commun, 2017. 492(4): p. 565-571.

23. Chambers, T.J., R.C. Weir, A. Grakoui, D.W. McCourt, J.F. Bazan, R.J. Fletterick, and C.M. Rice, Evidence that the N-terminal domain of nonstructural protein NS3 from yellow fever virus is a serine protease responsible for site-specific cleavages in the viral polyprotein. Proc Natl Acad Sci U S A, 1990. 87(22): p. 8898-902.

24. Lakowicz, J.R., Principles of fluorescence spectroscopy. 3rd ed. 2006, New York: Springer. xxvi, $954 \mathrm{p}$.

25. Gibson, D.G., L. Young, R.Y. Chuang, J.C. Venter, C.A. Hutchison, 3rd, and H.O. Smith, Enzymatic assembly of DNA molecules up to several hundred kilobases. Nat Methods, 2009. 6(5): p. 343-5.

26. Zhang J.H., Chung T.D., Oldenburg K.R, A Simple Statistical Parameter for Use in Evaluation and Validation of High Throughput Screening Assays. J Biomol Screen, 1999. 4(2): p. 67-73.

27. Shannon, A.E., M.M. Pedroso, K.J. Chappell, D. Watterson, S. Liebscher, W.M. Kok, D.P. Fairlie, G. Schenk, and P.R. Young, Product release is rate-limiting for catalytic processing by the Dengue virus protease. Sci Rep, 2016. 6: p. 37539.

28. Shin, D., R. Mukherjee, D. Grewe, D. Bojkova, K. Baek, A. Bhattacharya, L. Schulz, M. Widera, A.R. Mehdipour, G. Tascher, P.P. Geurink, A. Wilhelm, G.J. van der Heden van Noort, H. Ovaa, S. Muller, K.P. Knobeloch, K. Rajalingam, B.A. Schulman, J. Cinatl, G. Hummer, S. Ciesek, and I. Dikic, Papain-like protease regulates SARS-CoV- 2 viral spread and innate immunity. Nature, 2020.

29. Voss, S. and C. Nitsche, Inhibitors of the Zika virus protease NS2B-NS3. Bioorg Med Chem Lett, 2020. 30(5): p. 126965.

30. Billinger, E., J. Viljanen, S. Bergstrom Lind, and G. Johansson, Inhibition properties of free and conjugated leupeptin analogues. FEBS Open Bio, 2020.

31. Ghosh, A.K., J. Takayama, Y. Aubin, K. Ratia, R. Chaudhuri, Y. Baez, K. Sleeman, M. Coughlin, D.B. Nichols, D.C. Mulhearn, B.S. Prabhakar, S.C. Baker, M.E. Johnson, and A.D. Mesecar, Structure-based design, synthesis, and biological evaluation of a series of novel and reversible inhibitors for the severe acute respiratory syndrome- coronavirus papain-like protease. J Med Chem, 2009. 52(16): p. 5228-40. 
32. Lin, M.H., D.C. Moses, C.H. Hsieh, S.C. Cheng, Y.H. Chen, C.Y. Sun, and C.Y. Chou, Disulfiram can inhibit MERS and SARS coronavirus papain-like proteases via different modes. Antiviral Res, 2018. 150: p. 155-163.

33. Shiryaev, S.A., B.I. Ratnikov, A.V. Chekanov, S. Sikora, D.V. Rozanov, A. Godzik, J. Wang, J.W. Smith, Z. Huang, I. Lindberg, M.A. Samuel, M.S. Diamond, and A.Y. Strongin, Cleavage targets and the D-arginine-based inhibitors of the West Nile virus NS3 processing proteinase. Biochem J, 2006. 393(Pt 2): p. 503-11.

34. Leung, D., K. Schroder, H. White, N.X. Fang, M.J. Stoermer, G. Abbenante, J.L. Martin, P.R. Young, and D.P. Fairlie, Activity of recombinant dengue 2 virus NS3 protease in the presence of a truncated NS2B co-factor, small peptide substrates, and inhibitors. J Biol Chem, 2001. 276(49): p. 45762-71.

35. Liu, Y., Y. Song, V. Madahar, and J. Liao, Quantitative Forster resonance energy transfer analysis for kinetic determinations of SUMO-specific protease. Anal Biochem, 2012. 422(1): p. 14-21.

36. Nakata, H., T. Ohtsuki, and M. Sisido, A protease inhibitor discovery method using fluorescence correlation spectroscopy with position-specific labeled protein substrates. Anal Biochem, 2009. 390(2): p. 121-5.

37. Degorce, F., A. Card, S. Soh, E. Trinquet, G.P. Knapik, and B. Xie, HTRF: A technology tailored for drug discovery - a review of theoretical aspects and recent applications. Curr Chem Genomics, 2009. 3: p. 22-32. 


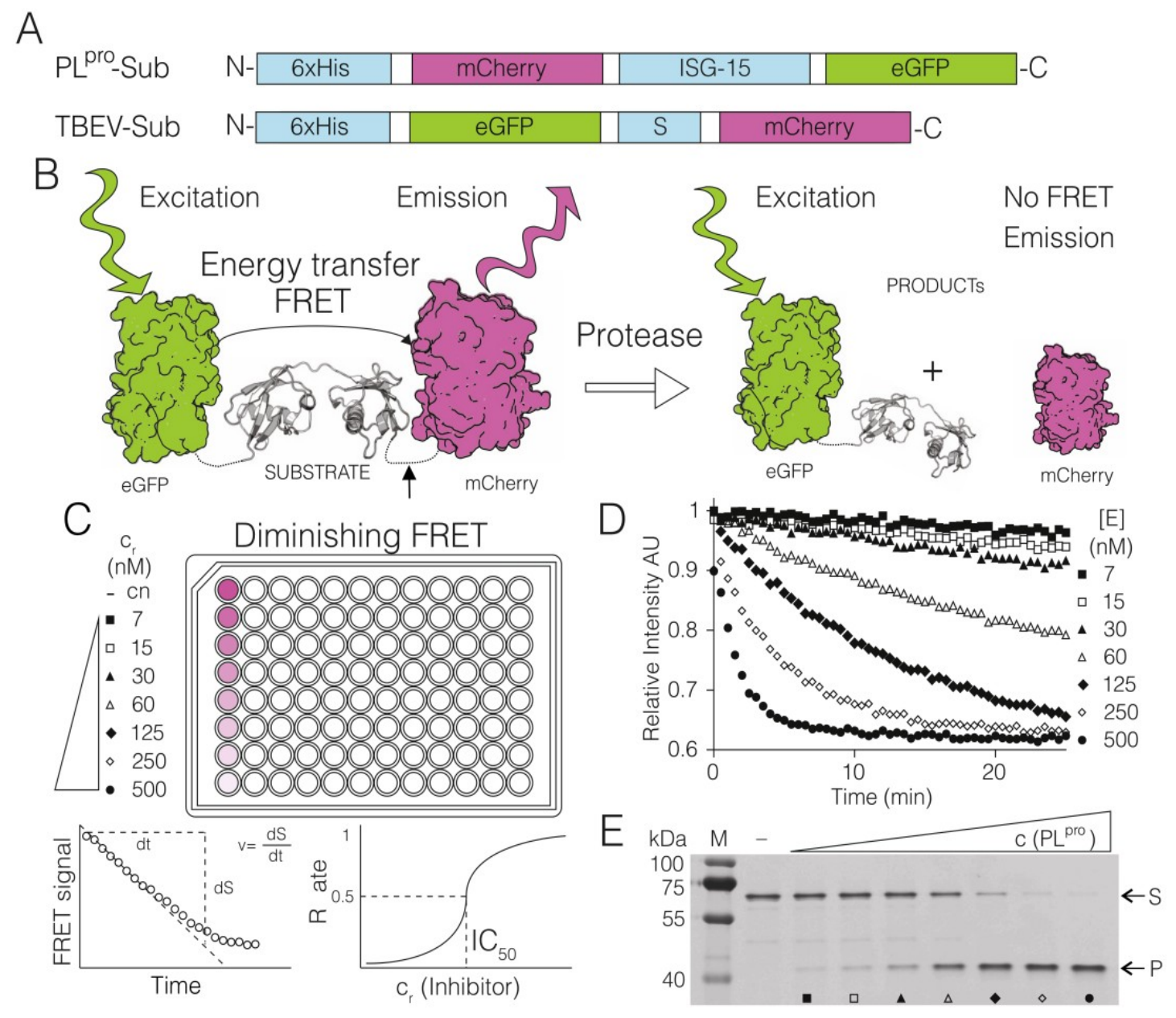

Figure 1: Substrates, principles of FRET assay and its optimization.

(A) The fluorescent PL ${ }^{\text {pro }}$ and NS2B-NS3 ${ }^{\text {pro }}$ substrates, (B) schematics of the FRET-based proteolytic assay, eGFP is excited with a green light at $488 \mathrm{~nm}$, FRET transfers the excitation to mCherry which emits the light that is detected. After proteolytic cleavage, this FRET signal is abolished, (C-D) the reaction of $\mathrm{PL}^{\text {pro }}$ substrate with a serial dilution of $\mathrm{PL}^{\text {pro }}$ enzyme $(500 \mathrm{nM}-10 \mathrm{nM})(\mathrm{C})$ raw data of reactions followed in the fluorescent plate reader (D) these reactions were loaded on SDS PAGE gel and visualized on a fluorescent scanner (E), where $(\mathrm{S})$-and $(\mathrm{P})$ donate substrate and product bands. 

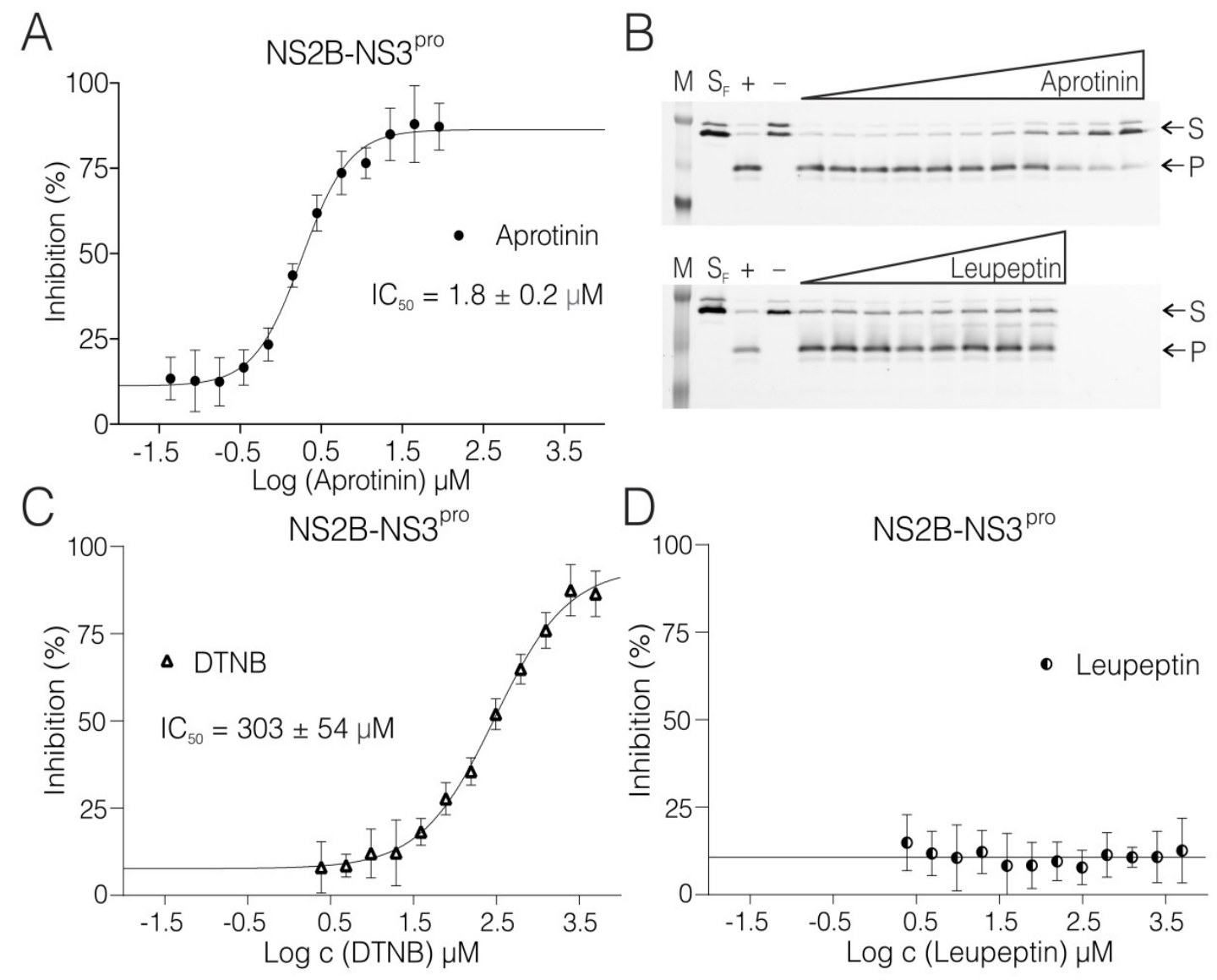

Figure 2: Inhibition of TBEV NS2B-NS3pro by small molecules.

Curves derived from the FRET inhibition assays of (A) aprotinin, (C) DTNB, and (D) leupeptin. Each curve is derived from three experiments. (B) Validation by SDS-PAGE analysis showing the successful inhibition by aprotinin (top) and no inhibition by leupeptin (bellow) where $(\mathrm{M})$ is a marker, $\left(\mathrm{S}_{\mathrm{F}}\right)$ is fresh substrate at reaction concentration, $(+)$ is positive control reaction where there was no inhibitor present, $(-)$ is negative control reaction where there was no enzyme present, $(S)$ is the substrate, $(P)$ is the product. The illustrative evaluations of the validation SDS-PAGE gels are shown in SI Figure 5. 


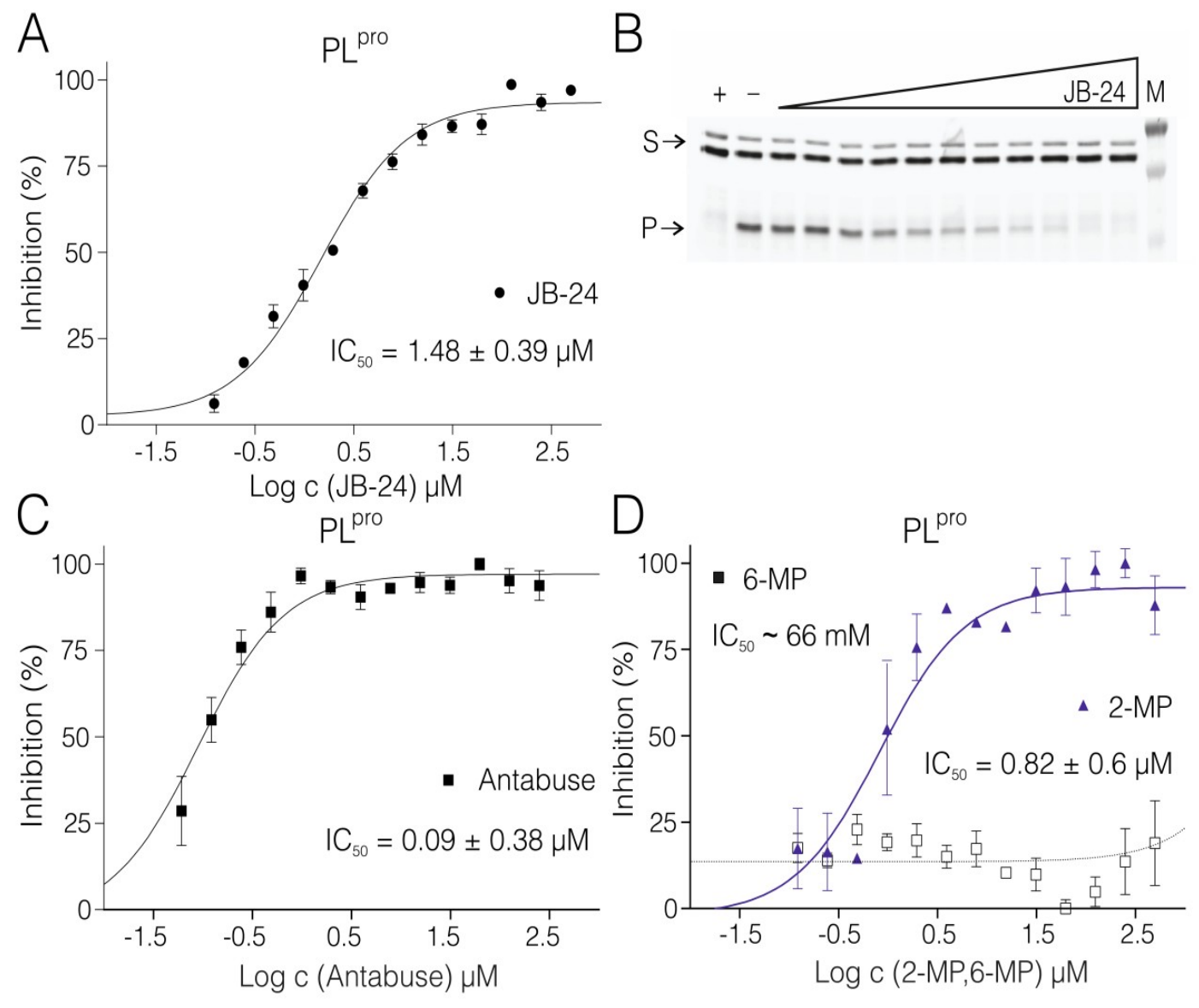

Figure 3: Inhibition of SARS-CoV2 PL ${ }^{\text {pro }}$ by small molecules.

Curves derived from the FRET inhibition assays of (A) JB24, (C) Antabuse, and (D) 2-MP and 6-MP. Each curve is derived from three experiments. (B) SDS PAGE gel from one of the titrations with JB24 where (M) is a marker, $(+)$ is a positive control reaction in which there was no inhibitor present, $(-)$ is a negative control reaction where there was no enzyme present, $(S)$ is the substrate, and $(P)$ is the product. The illustrative evaluations of the SDSPAGE gels resolving the reaction progress are shown in SI Figure 6. 